ORIGINAL ARTICLE

\title{
Gas stove use and respiratory health among adults with asthma in NHANES III
}

\author{
M D Eisner, P D Blanc
}

Occup Environ Med 2003;60:759-764

See end of article for authors' affiliations .....................

Correspondence to: DrM D Eisner, Assistant Professor of Medicine, University of California San Francisco, 350 Parnassus Ave, Ste 609 San Francisco, CA 94117, USA; eisner@itsa.ucsf.edu

Accepted 11 January 2003

\begin{abstract}
Background: Gas stoves release respiratory irritants, such as nitrogen dioxide and other combustion byproducts. Adults with asthma may be susceptible to the effects of gas stove exposure because of their underlying airway hyperresponsiveness, but this association has been difficult to establish.

Aims: To examine the association between gas stove use and respiratory health.

Methods: The analysis used data from the US Third National Health and Nutrition Examination Survey among 445 adults with asthma (representing 4.8 million persons with the condition).

Results: Nearly half of the adults with asthma had a gas stove in their home (47.1\%). There was no association between gas stove use and $\mathrm{FEV}_{1}$ (mean change $146 \mathrm{ml} ; 95 \% \mathrm{Cl}-50$ to $342 \mathrm{ml}$ ), $\mathrm{FVC}(0 \mathrm{ml}$; $95 \% \mathrm{Cl}-151$ to $152 \mathrm{ml}$ ), or $\mathrm{FEF}_{25 \%-75 \%}(357 \mathrm{ml} ; 95 \% \mathrm{Cl}-7$ to $722 \mathrm{ml}$ ). There was also no relation between gas stove use and the risk of self reported cough (OR $0.8 ; 95 \% \mathrm{Cl} 0.4$ to 1.7), wheeze (OR 1.5; $95 \% \mathrm{Cl} 0.7$ to 3.2 ), or other respiratory symptoms. Controlling for sociodemographic, smoking, housing, and geographic factors did not appreciably affect these results.

Conclusions: Among adults with asthma, there was no apparent impact of gas stove use on pulmonary function or respiratory symptoms. These results should be reassuring to adults with asthma and their health
\end{abstract} care providers.
B ecause the morbidity and mortality from adult asthma have markedly increased during the past two decades in the United States and other developed nations, ${ }^{1}$ increasing interest has focused on how the "western lifestyle" may adversely affect persons with asthma. ${ }^{2}$ Air pollution, in particular, has been one of the environmental factors suspected of causing asthma morbidity. As outdoor air quality has improved in recent years, the potential impact of indoor air pollution on respiratory health has become more relevant. ${ }^{3}$

Gas stove use, a major source of indoor combustion, releases respiratory irritants such as nitrogen dioxide and other combustion by-products. ${ }^{34}$ Limited evidence suggests that gas stove use could negatively affect adults with asthma, but the findings have been inconsistent. ${ }^{5}{ }^{6}$ Using data from the population based Third National Health and Nutrition Examination Survey (NHANES III), we examined the association between gas stove use and respiratory health among adults with asthma.

\section{MATERIALS AND METHODS \\ Overview}

We used data from the US Third National Health and Nutrition Examination Survey (NHANES III), which was conducted by the National Center for Health Statistics of the Centers for Disease Control and Prevention between 1988 and $1994 .^{7}$ This survey employed a stratified, multistage probability design to select a representative sample of the civilian, non-institutionalised US population. Conducted in participant households, interviews elicited demographic and health information. In specially equipped mobile examination centres or their homes, participants had a standardised examination performed, which included pulmonary function testing. In this study, we analysed the cross sectional association between gas stove exposure and respiratory health among adults with asthma. The primary NHANES III study was approved by the National Center for Health Statistics Institutional Review Board; the present analysis was certified as an exempt category of research by the UCSF Committee on Human Research.

\section{Classification of asthma}

The NHANES III survey interviews ascertained selected chronic health conditions, including asthma. Subjects were asked whether they had ever received a physician's diagnosis of asthma: "Has a doctor ever told you that you had asthma?" Respondents who indicated ever having asthma were then asked if they currently had the condition. In this study, adults with asthma were defined as adults who reported current asthma. To reduce misclassification with smoking related chronic obstructive pulmonary disease, we further defined asthma by excluding those subjects who also reported ever having a physician's diagnosis of emphysema. $^{89}$

\section{Study sample}

In the current study, the primary analysis included nonsmoking adult NHANES III participants aged 17 years or greater who had current asthma and available spirometry data. Of the 20050 adult participants, 826 indicated current asthma. Of these participants, the analysis excluded 268 persons for current smoking (self reported smoking or serum cotinine $\geqslant 14 \mathrm{ng} / \mathrm{ml}$, which is consistent with active smoking). ${ }^{10}{ }^{11}$ An additional 95 subjects were excluded who did not have spirometry performed or had unreliable spirometry results. Another 18 subjects were excluded who were not members of the three race/ethnicity groups from whom predictive pulmonary function values were previously derived for NHANES III (white, non-Hispanic; African-American; or Mexican-American). ${ }^{12}$ As a secondary analysis, we examined

Abbreviations: ETS, environmental tobacco smoke; FEF, forced expiratory flow; FEV, forced expiratory volume; FVC, forced vital capacity 
Main messages

- There was no apparent association between gas stove use and pulmonary function impairment among adults with asthma.

- In adults with asthma, there was also no relation between gas stove use and respiratory symptoms.

the larger sample of all 7630 adult lifelong never smoking participants with reliable spirometry and available predictive pulmonary function values.

\section{Assessment of gas stove exposure and other housing characteristics}

Interviews included a series of questions about housing characteristics. The presence of a gas stove was ascertained by the following question: "Is a gas stove or oven used for cooking at this place?" More detailed questions about gas stove use, such as frequency of use, were not included in the NHANES III interview, nor was any direct inspection of the home performed.

Based on survey items, we examined other housing characteristics that are potentially related to gas stove use and respiratory status. We classified home heating as gas fuelled when respondents indicated that they used a gas fuelled furnace or space heater to heat their home during the past 12 months. To assess the age of the home, subjects were asked when the home was built in several categories: <1946, 1946-73, and $\geqslant 1974$. Domestic environmental tobacco smoke (ETS) exposure was defined as an affirmative answer to the question, "Does anyone who lives here smoke cigarettes in the home?"

We also examined geographic characteristics that may affect the prevalence of gas stove use. Based on Bureau of Census definitions, the NHANES III classified subjects as residing in four broad geographic regions of the United States (East, South, Midwest, and West). ${ }^{7}$ Area of residence was also classified as rural or urban based on USDA urban-rural codes (that is, urban $=$ central counties or fringe counties of metropolitan areas of $\geqslant 1$ million people). ${ }^{7}$

\section{Sociodemographic characteristics, smoking, and atopy}

In the analysis, we evaluated demographic characteristics that are potentially related to gas stove use. Education, a key socioeconomic indicator, was ascertained as the highest grade or year of school completed. As a measure of income, the analysis used the poverty income ratio, which reflects the ratio of family income to the federal poverty threshold. ${ }^{7}$ The survey ascertained race/ethnicity in a standardised manner. For this analysis, race/ethnicity were defined as white, nonHispanic, African-American, and Mexican-American, which correspond to the groups with available predicted spirometry values. $^{12}$

Personal cigarette smoking was ascertained using standard questions developed for the National Health Interview Survey. In this analysis, previous smoking was defined as an affirmative answer to ever smoking ("Have you smoked at least 100 cigarettes during your entire life?") and no current smoking. ${ }^{13}$

NHANES III conducted skin testing in subjects aged 6-19 years and a random half sample of adults aged 20-59 years. Skin test results were available for 179 adults with asthma. Using these data, we defined atopy as a positive skin test result to any of eight common aeroallergens: white oak, dust

\section{Policy implications}

- There was no evidence that gas stove exposure adversely affects the respiratory health of adults with asthma. Public policies should be aimed at environmental exposures that have been shown to exacerbate asthma, such as environmental tobacco smoke exposure.

mite, cat, Alternaria, rye grass, Russian thistle, Bermuda grass, or ragweed.

\section{Pulmonary function measurement}

Spirometry was performed according to the 1987 American Thoracic Society recommendations. ${ }^{14}$ Examinees performed 5-8 forced expiratory manoeuvres. To classify tests for reliability, all tests were reviewed by two senior quality technicians at the spirometry quality control centre. ${ }^{15}$ In the present analysis, only reliable test results were included.

We used predicted pulmonary function values that were previously derived from lifelong non-smoking NHANES III participants without any reported history of asthma, other respiratory diseases, or respiratory symptoms. ${ }^{12}$ These predictive equations are based on age, sex, height, and three race-ethnicity groups (white, non-Hispanic, AfricanAmerican, and Mexican-American).

\section{Respiratory symptoms}

In this analysis, we also evaluated the association between gas stove use and respiratory symptoms. The survey ascertained chronic cough ("Do you usually cough on most days for three consecutive months or more during the year?") and phlegm production ("Do you bring up phlegm on most days for three consecutive months or more during the year?"). The interview also assessed dyspnoea with exertion ("Are you troubled by shortness of breath when hurrying on level ground or walking up a slight hill?") and wheezing ("Have you had wheezing or whistling in your chest at any time in the past 12 months?").

\section{Statistical analysis}

Statistical analysis was performed with SAS 8.2 (SAS Institute, Cary, NC) and SUDAAN 8.0 (Research Triangle Institute, NC). In all analyses, sampling weights were used to adjust for unequal probabilities of selection and to account for non-response. SUDAAN was used to calculate variance estimates that account for the complex survey design. ${ }^{16}$

For bivariate comparisons, linear regression analysis was used for normally distributed continuous variables, and the $\chi^{2}$ test for categorical variables. For each pulmonary function value, we calculated residuals, which are observed minus predicted values, ${ }^{12}$ adjusted for age, sex, height, and raceethnicity.

A primary analytical aim was to determine the cross sectional association between gas stove use and each pulmonary function residual among adults with asthma. The difference in mean residual reflects the mean increment or decrement in pulmonary function associated with gas stove use. Because there was no evidence of statistical interaction by sex ( $p>0.15$ for all measures), we did not stratify results by this variable.

Linear regression analysis was conducted to evaluate the relation between gas stove use and each pulmonary function residual. Multivariate linear regression was then performed to control for the potential confounding effects of previous smoking history and socioeconomic status (educational attainment and poverty income ratio). The model can be 
summarised as: pulmonary function residual (age, gender, race, and height adjusted) $=$ intercept + previous smoking history + educational attainment + poverty income ratio.

A subsequent analysis also controlled for housing and geographic factors, including geographic location, urban versus rural location, domestic ETS exposure, and gas fuelled heating systems (versus other). This model can be summarised as: pulmonary function residual (age, gender, race, and height adjusted) = intercept + previous smoking history + educational attainment + poverty income ratio + age of home + urban versus rural location + geographic region + domestic ETS exposure + home gas heating. Furthermore, interactions between gas stove use and sex, heating fuel type (gas versus other), domestic ETS exposure, rural location, and atopy were examined. In these analyses, there was no statistical evidence of interaction $(\mathrm{p}>0.05)$.

To examine the impact of gas stove use on respiratory symptoms, logistic regression analysis was used in similar fashion. Three sets of analyses controlled for age, gender, race-ethnicity; additional socioeconomic indicators and smoking history; and additional housing and geographic factors.

Linear regression model assumptions and fit were confirmed using plots of studentised residuals versus predicted values and normal probability plots. Logistic regression model fit was confirmed using the Hosmer-Lemeshow goodness of fit test.

As a secondary analysis, we repeated the entire set of analyses in a larger group of all 7630 adult lifelong never smoking NHANES III participants. This strategy provided greater statistical power for estimating the impact of gas stove use. In addition, this analysis assessed the specificity of results to adults with asthma, as opposed to the broader target population of all never smoking adults.

We estimated statistical power for the association between gas stove exposure and several key study outcomes. In all cases, we used a two tailed alpha of 0.05 . The study had $80 \%$ power to detect a gas stove related reduction of $\mathrm{FEV}_{1}$ and FVC of 153 and $145 \mathrm{ml}$, respectively. Consequently, the study had adequate power to detect effects that are substantially smaller than those observed for another major indoor combustion product, environmental tobacco smoke. ${ }^{17}$ For dichotomous outcomes, the study had $99 \%$ power to detect a relative risk of 1.5 for wheezing and 1.2 for any respiratory symptom.

\section{RESULTS}

Nearly half of adults with asthma had a gas stove in their home $(47.1 \%)$. Gas stove use was associated with several housing and geographic factors, including older homes, nonrural location, northeastern or western location (increased and decreased, respectively), and homes with a gas heating system (table 1). There was a suggestion that gas stoves were more common in homes of female and non-white respondents.

There was no indication that gas stove use was associated with a decrement in $\mathrm{FEV}_{1}, \mathrm{FVC}, \mathrm{FEV}_{1} / \mathrm{FVC}$ ratio, or $\mathrm{FEF}_{25 \%-75 \%}$ (table 2). Although the $95 \%$ confidence interval included no association, mean $\mathrm{FEV}_{1}$ and $\mathrm{FEF}_{25 \%-75 \%}$ appeared higher among those with gas stoves. Moreover, gas stove use was statistically related to a higher mean $\mathrm{FEV}_{\mathrm{l}} / \mathrm{FVC}$ ratio. Controlling for socioeconomic, smoking, housing, and geographic variables did not substantively affect this pattern of results.

Gas stove use was not associated with chronic cough or phlegm production among adults with asthma (table 3). In contrast, gas stove use was related to a greater risk of dyspnoea, wheeze, and any respiratory symptom, but the $95 \%$ confidence intervals did not exclude no relationship.

Among the larger group of 7630 lifelong never smokers, the results generally mirrored those for adults with asthma. There was no association between gas stove use and $\mathrm{FEV}_{1}$ or FVC in any linear regression model (table 4). Gas stove use was related to a greater mean $\mathrm{FEV}_{1} / \mathrm{FVC}$ ratio and

\begin{tabular}{|c|c|c|c|}
\hline Variable & Gas stove & No gas stove & $p$ value for difference \\
\hline \multicolumn{4}{|l|}{ Sample characteristics } \\
\hline Sample size (unweighted) & 251 & 194 & - \\
\hline Estimated population (weighted) & $2,235,392$ & $2,515,535$ & - \\
\hline \multicolumn{4}{|l|}{ Personal characteristics } \\
\hline Age, mean (SE) & $42.3(1.4)$ & $42.4(1.7)$ & 0.96 \\
\hline Sex (\% female) & $71 \%$ & $61 \%$ & 0.10 \\
\hline Race/ethnicity & & & 0.11 \\
\hline White, non-Hispanic (\%) & $76 \%$ & $85 \%$ & \\
\hline African-American (\%) & $17 \%$ & $12 \%$ & \\
\hline Mexican-American (\%) & $6 \%$ & $3 \%$ & \\
\hline \multicolumn{4}{|l|}{ Socioeconomic/smoking variables } \\
\hline Previous cigarette smoking (\%) & $36 \%$ & $34 \%$ & 0.77 \\
\hline Education, mean years (SE) & $12.7(0.4)$ & $13.0(0.3)$ & 0.48 \\
\hline Poverty-income ratio, mean (SE) & $3.0(0.2)$ & $3.3(0.2)$ & 0.37 \\
\hline \multicolumn{4}{|l|}{ Housing/geographic factors } \\
\hline Age of home & & & 0.0006 \\
\hline$<1946$ & $37 \%$ & $13 \%$ & \\
\hline $1946-73$ & $40 \%$ & $41 \%$ & \\
\hline$>1974$ & $16 \%$ & $40 \%$ & \\
\hline Unknown or not reported & $7 \%$ & $6 \%$ & \\
\hline Rural location (\%) & $38 \%$ & $59 \%$ & 0.003 \\
\hline Geographic location & & & 0.09 \\
\hline Northeast (\%) & $28 \%$ & $18 \%$ & \\
\hline South (\%) & $22 \%$ & $21 \%$ & \\
\hline Midwest (\%) & $21 \%$ & $17 \%$ & \\
\hline West (\%) & $29 \%$ & $44 \%$ & \\
\hline Lives with $\geqslant 1$ smokers (\%) & $18 \%$ & $13 \%$ & 0.39 \\
\hline Gas heating system (\%) & $61 \%$ & $34 \%$ & 0.006 \\
\hline
\end{tabular}

Sample included all non-smoking adults aged 17 years or greater with asthma who had reliable spirometry results. Proportions are column proportions. 
Table 2 Gas stove exposure and pulmonary function among adults with asthma participating in NHANES III

\begin{tabular}{llll}
\hline & \multicolumn{2}{l}{ Change in mean pulmonary function value $(95 \% \mathrm{Cl})^{*}$, adjusting for: } \\
\cline { 2 - 4 } $\begin{array}{l}\text { Pulmonary function } \\
\text { measurement }\end{array}$ & $\begin{array}{l}\text { Age, gender, height, and } \\
\text { race-ethnicity }\end{array}$ & $\begin{array}{l}\text { Socioeconomic indicators } \\
\text { and smoking historyt }\end{array}$ & $\begin{array}{l}\text { Housing and geographic } \\
\text { factors }\end{array}$ \\
\hline $\mathrm{FEV}_{1}(\mathrm{ml})$ & $146(-50$ to 342$)$ & $136(-59$ to 331$)$ & $136(-46$ to 317$)$ \\
$\mathrm{FVC} \mathrm{(ml)}$ & $0(-151$ to 152$)$ & $-8.7(-152$ to 135$)$ & $30(-109$ to 170$)$ \\
$\mathrm{FEV}_{1} / \mathrm{FVC}$ ratio (\%) & $4.1(0.47$ to 7.63$)$ & $3.96(0.33$ to 7.59$)$ & $3.62(0.40$ to 6.84$)$ \\
$\mathrm{FEF}_{25 \%-75 \%}$ & $357(-7$ to 722$)$ & $345(-30$ to 719$)$ & $307(-50$ to 665$)$ \\
\hline
\end{tabular}

*Residual values calculated as observed minus expected values. Expected values derived from Hankinson equations based on age, gender, race-ethnicity (white, African-American, Mexican American), and height. First column shows association between gas stove use and mean increase or decrease in each pulmonary function measurement, adjusted using predictive equations. Second and third columns also control for additional covariates in multivariate linear regression models. See methods for further analysis details.

†Socioeconomic indicators: educational attainment and poverty-income ratio.

tHousing and geographic factors: age of home (<1946, 1946-73, 1974+, or unknown), urban versus rural location, geographic location (northeast, south, midwest, west), residence with $\geqslant 1$ smokers (versus none), gas heating system (versus other fuel).

Results based on linear regression analysis. Results in each column also control for covariates in previous column.

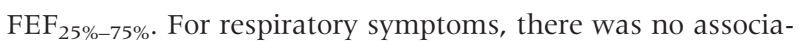
tion between gas stove use and phlegm production, dyspnoea, or wheezing in logistic regression models controlling for the three sets of covariates (data not shown, $\mathrm{p}>0.15$ ). In the analysis controlling for age, race/ethnicity, and gender, gas stove use was related to a greater risk of chronic cough (OR 1.3; 95\% CI 0.9 to 1.8). After controlling for the full set of socioeconomic, housing, and geographic covariates, the risk estimate appeared stronger (OR 1.6; 95\% CI 1.1 to 2.3 ).

\section{DISCUSSION}

Gas stove use is widespread among adults with asthma. Because gas cooking releases respiratory irritants, this exposure has potential to negatively affect the respiratory health of adults with asthma. However, we found no evidence of pulmonary function impairment among adults with asthma who reside in homes with gas stove use. Moreover, there was no association between gas stove exposure and respiratory symptoms. In the general population of adult lifelong non-smokers, there was also no clear evidence of adverse effects on respiratory health.
The likelihood of gas stove exposure varies by geographic and socioeconomic factors that could also affect asthma status. Our results were in accordance with previous data from the American Housing Survey conducted by the US Bureau of the Census, which found that homes with gas stoves are more likely to have urban location, older construction, moderate to severe physical problems, African-American or Hispanic ownership, and low income residents. ${ }^{18}$ Because these factors may be associated with asthma severity, ${ }^{39}{ }^{20}$ confounding could affect the observed relation between gas stove use and respiratory health. Given the lack of association between gas stove use and respiratory health, negative confounding would be of particular concern. However, controlling for these variables did not affect our study conclusions.

There are few previous studies that have examined the impact of gas stove exposure on adults with asthma. In a panel study of adults with asthma, gas stove use was associated with an increased risk of respiratory symptoms, restricted activity, and emergency department visits. Another time-series analysis found a deleterious impact of gas stove use on daily peak expiratory flow rate and

Table 3 Gas stove exposure and respiratory symptoms among adults with asthma participating in NHANES III

\begin{tabular}{|c|c|c|c|c|}
\hline \multirow[b]{2}{*}{$\begin{array}{l}\text { Respiratory } \\
\text { symptom }\end{array}$} & \multirow[b]{2}{*}{$\begin{array}{l}\text { Proportion reporting } \\
\text { symptom }\end{array}$} & \multicolumn{3}{|l|}{ Odds ratio $(95 \%$ Cl) } \\
\hline & & $\begin{array}{l}\text { Age, gender, and } \\
\text { race-ethnicity }\end{array}$ & $\begin{array}{l}\text { Socioeconomic } \\
\text { indicators and } \\
\text { smoking history* }\end{array}$ & $\begin{array}{l}\text { Housing and } \\
\text { geographic factors }\end{array}$ \\
\hline \multicolumn{5}{|l|}{ Cough } \\
\hline $\begin{array}{l}\text { Usual cough for } \\
\geqslant 3 \mathrm{mth} / \mathrm{y}\end{array}$ & $16 \%$ & $0.8(0.4$ to 1.7$)$ & $0.8(0.3$ to 1.7$)$ & $1.1(0.6$ to 2.1$)$ \\
\hline \multicolumn{5}{|l|}{ Phlegm production } \\
\hline $\begin{array}{l}\text { Usually brings up } \\
\text { phlegm } \geqslant 3 \mathrm{mth} / \mathrm{y}\end{array}$ & $13 \%$ & 0.7 (0.3 to 1.7$)$ & $0.7(0.3$ to 1.6$)$ & $0.7(0.3$ to 1.8$)$ \\
\hline \multicolumn{5}{|c|}{ Dyspnoea } \\
\hline $\begin{array}{l}\text { Hurrying to level } \\
\text { ground or walking } \\
\text { uphill }\end{array}$ & $45 \%$ & $1.4(0.8$ to 2.6$)$ & $1.4(0.8$ to 2.6$)$ & $1.4(0.8$ to 2.7$)$ \\
\hline \multicolumn{5}{|l|}{ Wheeze } \\
\hline $\begin{array}{l}\text { Any time during } \\
\text { past } 12 \text { months }\end{array}$ & $67 \%$ & 1.5 (0.7 to 3.20 & $1.6(0.8$ to 3.4$)$ & $1.6(0.7$ to 3.4$)$ \\
\hline $\begin{array}{l}\text { Any respiratory } \\
\text { symptom }\end{array}$ & $80 \%$ & $1.5(0.7$ to 3.3$)$ & $1.6(0.8$ to 3.2$)$ & $1.7(0.7$ to 3.7$)$ \\
\hline
\end{tabular}

*Socioeconomic indicators: educational attainment and poverty-income ratio.

†Housing and geographic factors: age of home (<1946, 1946-73, 1974+, or unknown), urban versus rural location, geographic location (northeast, south, midwest, west), residence with $\geqslant 1$ smokers (versus none), gas heating system (versus other fuel).

Results based on logistic regression analysis. Results in each column also control for covariates in previous column. 
Table 4 Gas stove exposure and pulmonary function among 7630 lifelong never smoking adult participants in NHANES III

\begin{tabular}{|c|c|c|c|}
\hline \multirow[b]{2}{*}{$\begin{array}{l}\text { Pulmonary function } \\
\text { measurement }\end{array}$} & \multicolumn{3}{|c|}{ Change in mean pulmonary function value $(95 \% \mathrm{Cl})^{*}$} \\
\hline & $\begin{array}{l}\text { Age, gender, height, and } \\
\text { race-ethnicity }\end{array}$ & Socioeconomic indicators $†$ & $\begin{array}{l}\text { Housing and geographic } \\
\text { factors } \neq\end{array}$ \\
\hline 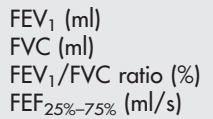 & $\begin{array}{l}21(-5 \text { to } 48) \\
0.8(-28 \text { to } 29) \\
0.52(0.09 \text { to } 0.95) \\
86(20 \text { to } 151)\end{array}$ & $\begin{array}{l}27(-0.8 \text { to } 54) \\
7(-23 \text { to } 36) \\
0.50(0.05 \text { to } 0.95) \\
90(22 \text { to } 159)\end{array}$ & $\begin{array}{l}13(-15 \text { to } 41) \\
-14(-48 \text { to } 21) \\
0.58(0.15 \text { to } 1.01) \\
82(19 \text { to } 145)\end{array}$ \\
\hline
\end{tabular}

*Residual values calculated as observed minus expected values. Expected values derived from Hankinson equations based on age, gender, race-ethnicity (white, African-American, Mexican American), and height.

†Socioeconomic indicators: educational attainment and poverty-income ratio.

fHousing and geographic factors: age of home $(<1946,1946-73,1974+$, or unknown), urban versus rural location, geographic location (northeast, south, midwest, west), residence with $\geqslant 1$ smokers (versus none), gas heating system (versus other fuel).

Results based on linear regression analysis. Results in each column also control for covariates in previous column.

respiratory symptoms. ${ }^{21}$ Among current adult asthmatics living in the UK, gas stove use was associated with a modest decrement in $\mathrm{FEV}_{1}, \mathrm{FVC}$, and $\mathrm{FEV}_{1} / \mathrm{FVC}$ ratio in cross sectional analysis. ${ }^{6}$ However, in the longitudinal follow up component of this study, there was no impact of gas stove exposure on respiratory symptoms among adults with asthma, such as wheeze and dyspnoea. In a longitudinal cohort study of adults with asthma, we found no impact of gas stove use on asthma severity, health status, or health care utilisation for asthma. ${ }^{22}$ Overall, the evidence has not conclusively indicated that gas stove use adversely affects adults with asthma.

An important study limitation may be the method of gas stove exposure assessment. The NHANES III interview ascertained self reported gas stove use in the household, rather than personal cooking behaviour or actual measurements of nitrogen dioxide $\left(\mathrm{NO}_{2}\right)$. Because $\mathrm{NO}_{2}$ levels are highest in the kitchen during gas stove cooking, ${ }^{23}$ this survey item could overestimate exposure for respondents who do not regularly cook. Additional bias could result if adults with more symptomatic, severe asthma were less likely to cook themselves. In a cross sectional study, these effects would attenuate any adverse impact of gas stove use on respiratory health. Indeed, this potential bias could explain the relation between gas stove use and greater mean $\mathrm{FEV}_{\mathrm{l}} / \mathrm{FVC}$ ratio. Moreover, this could explain why gas stove use appeared to be associated with cough among the general population of never smokers, but not among adults with asthma who may, because of their respiratory symptoms, avoid cooking.

The use of self reported exposure to gas stoves also does not assess possible differences in the characteristics of gas or gas fuelled cooking equipment that could influence respiratory effects. Supporting this possibility, the respiratory effects of gas stove use appear to vary by country of residence. ${ }^{24}$

Other aspects of timing and intensity of exposure could also be important. A study of 16 non-smoking asthmatic women found that acute peak $\mathrm{NO}_{2}$ exposure during gas cooking was associated with diminished peak expiratory flow rate, whereas mean $\mathrm{NO}_{2}$ exposure over a two week period had no effect. ${ }^{25}$ The deleterious consequences of acute peak $\mathrm{NO}_{2}$ exposure on adults with asthma are supported by epidemiological studies that assessed gas stove use on a daily basis ${ }^{521}$ and controlled human exposure studies of acute $\mathrm{NO}_{2}$ exposure. ${ }^{26-29}$ Average daily gas stove exposure, as assessed by the present study, may have less or no impact on adults with asthma.

The definition of asthma based on self reported physician diagnosis comprises another study limitation. There is no "gold standard" for defining asthma in epidemiological surveys. ${ }^{30}$ The majority of subjects indicated current respiratory symptoms, consistent with previous reports. ${ }^{91}$ To reduce misclassification with chronic obstructive pulmonary disease, we excluded subjects who also reported a diagnosis of emphysema. Even so, we cannot exclude the possibility of asthma misclassification.

Overall, the present study should be reassuring to adults with asthma and their healthcare providers. Although there are limitations to this cross sectional design, there was no apparent impact of gas stove exposure on the respiratory health of adults with asthma. In terms of indoor exposures, environmental tobacco smoke exposure appears to be a far greater concern for adults with asthma, as supported by our previous analysis of NHANES III. ${ }^{17}{ }^{32-34}$ It appears unlikely that cooking with gas stoves has contributed significantly to the recent rise in worldwide asthma morbidity and mortality.

\section{ACKNOWLEDGEMENTS}

This work was supported by K23 HL04201 from the National Heart, Lung, and Blood Institute, National Institutes of Health.

\section{Authors' affiliations}

M D Eisner, P D Blanc, Division of Occupational and Environmental Medicine, Department of Medicine, University of California, San Francisco, USA

\section{REFERENCES}

1 Mannino DM, Homa DM, Pertowski CA, et al. Surveillance for asthmaUnited States, 1960-1995. Morb Mortal Wkly Rep Surveill Summ 1998:47:1-27.

2 Alm JS, Swartz J, Lilia G, et al. Atopy in children of families with an anthroposophic lifestyle. Lancet 1999;353:1485-8.

3 Samet JM, Marbury MC, Spengler JD. Health effects and sources of indoor air pollution. Part I. Am Rev Respir Dis 1987;136:1486-508.

4 Jarvis D, Chinn S, Luczynska C, et al. Association of respiratory symptoms and lung function in young adults with use of domestic gas appliances. Lancet 1996;347:426-31.

5 Ostro BD, Lipsett MJ, Mann JK, et al. Indoor air pollution and asthma. Results from a panel study. Am J Respir Crit Care Med 1994;149:1400-6.

6 Moran SE, Strachan DP, Johnston ID, et al. Effects of exposure to gas cooking in childhood and adulthood on respiratory symptoms, allergic sensitization and lung function in young British adults. Clin Exp Allergy 1999;29:1033-41.

7 National Center for Health Statistics. Plan and operation of the Third National Health and Nutrition Examination Survey, 1988-1994, Vol. DHHS Publication No. PHS 94-1308. Washington, DC: US Department of Health and Human Services, 1994.

8 McWhorter WP, Polis MA, Kaslow RA. Occurrence, predictors, and consequences of adult asthma in NHANESI and follow-up survey. Am Rev Respir Dis 1989;139:721-4.

9 Dodge R, Cline MG, Burrows B. Comparisons of asthma, emphysema, and chronic bronchitis diagnoses in a general population sample. Am Rev Respir Dis 1986;133:981-6.

10 Jarvis MJ, Tunstall-Pedoe H, Feyerabend C, et al. Comparison of tests used to distinguish smokers from nonsmokers. Am J Public Health 1987:77:1435-8.

11 Cummings SR, Richard RJ. Optimum cutoff points for biochemical validation of smoking status. Am J Public Health 1988;78:574-5.

12 Hankinson JL, Odencrantz JR, Fedan KB. Spirometric reference values from a sample of the general U.S. population. Am J Respir Crit Care Med 1999;159:179-87. 
13 Anon. Cigarette smoking among adults - United States, 1991 [published erratum appears in MMWR Morb Mortal Wkly Rep 1993;42:255]. MMWR Morb Mortal Wkly Rep 1993;42:230-3.

14 American Thoracic Society. Standardization of spirometry-1987 update. Statement of the American Thoracic Society. Am Rev Respir Dis 1987; 136:1285-98

15 National Center for Health Statistics. NHANES III Reference Manuals and Reports. CD-ROM No. 6-0178 (1096). Hyattsville, MD: Data Dissemination Branch, 1996.

16 Shah BV, Barnwell BG, Bieler GS. SUDAAN User's Manual. Release 7.0. Research Triangle Park, NC: Research Triangle Institute, 1996.

17 Eisner MD. Environmental tobacco smoke exposure and pulmonary function among adults in NHANES III: impact on the general population and adults with current asthma. Environ Health Perspect 2002;1 10:765-70.

18 US Departments of Commerce and Housing and Urban Development American Housing Survey for the United States in 1995. Washington, DC: US Department of Commerce, Bureau of the Census and US Department of Housing and Urban Development, 1997.

19 Ray NF, Thamer M, Fadillioglu B, et al. Race, income, urbanicity, and asthma hospitalization in California: a small area analysis. Chest 1998;113:1277-84

20 Eisner MD, Katz PP, Yelin EH, et al. Risk factors for hospitalization among adults with asthma: the influence of sociodemographic factors and asthma severity. Respir Res 2001 ;2:53-60.

21 Lebowitz MD, Collins L, Holberg CJ. Time series analyses of respiratory responses to indoor and outdoor environmental phenomena. Environ Res 1987;43:332-41.

22 Eisner MD, Yelin EH, Katz PP, et al. Exposure to indoor combustion and adult asthma outcomes: environmental tobacco smoke, gas stoves, and woodsmoke. Thorax 2002;57:973-8.

23 Goldstein IF, Lieber K, Andrews LR, et al. Acute respiratory effects of short-term exposures to nitrogen dioxide. Arch Environ Health 1988;43:138-42.
24 Jarvis D, Chinn S, Sterne J, et al. The association of respiratory symptoms and lung function with the use of gas for cooking. European Community Respiratory Health Survey. Eur Respir J 1998;11:651-8.

$25 \mathrm{Ng}$ TP, Seet CS, Tan WC, et al. Nitrogen dioxide exposure from domestic gas cooking and airway response in asthmatic women. Thorax 2001;56:596-601

26 Tunnicliffe WS, Burge PS, Ayres JG. Effect of domestic concentrations of nitrogen dioxide on airway responses to inhaled allergen in asthmatic patients. Lancet 1994:344:1733-6.

27 Salome CM, Brown NJ, Marks GB, et al. Effect of nitrogen dioxide and other combustion products on asthmatic subjects in a home-like environment. Eur Respir J 1996;9:910-18.

28 Orehek J, Massari JP, Gayrard P, et al. Effect of short-term, low-level nitrogen dioxide exposure on bronchial sensitivity of asthmatic patients. J Clin Invest 1976;57:301-7.

29 Jenkins HS, Devalia JL, Mister RL, et al. The effect of exposure to ozone and nitrogen dioxide on the airway response of atopic asthmatics to inhaled allergen: dose- and time-dependent effects. Am J Respir Crit Care Med 1999;160:33-9.

30 Toraen K, Brisman J, Jearvholm B. Asthma and asthma-like symptoms in adults assessed by questionnaires. A literature review. Chest 1993;104:600-8.

31 Legorreta AP, Christian-Herman J, O'Connor RD, et al. Compliance with national asthma management guidelines and specialty care: a health maintenance organization experience. Arch Intern Med 1998;158:457-64.

32 Eisner MD, Blanc PD. Environmental tobacco smoke and adult asthma. In: Watson R, ed. Environmental tobacco smoke. Boca Raton, FL: CRC Press, 2001:81-105.

33 Eisner MD, Katz PP, Yelin EH, et al. Measurement of environmental tobacco smoke exposure among adults with asthma. Environ Health Perspect $2001 ; 109: 809-14$

34 Sippel JM, Pedula KL, Vollmer WM et al. Associations of smoking with hospital-based care and quality of life in patients with obstructive airway disease. Chest 1999;115:691-6.

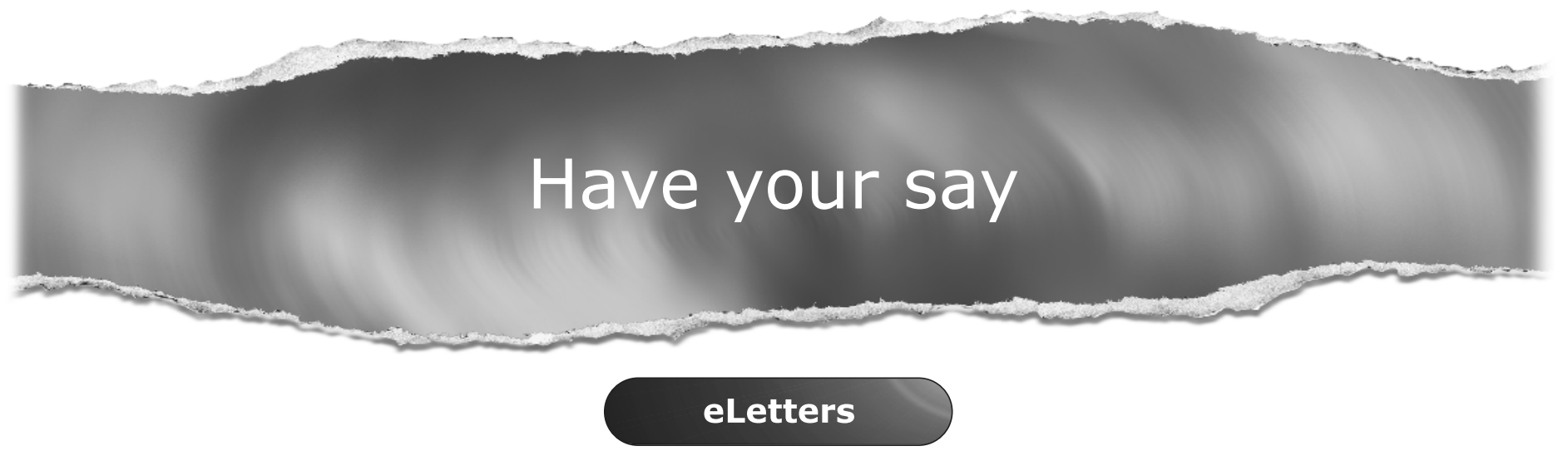

If you wish to comment on any article published in Occupational and Environmental Medicine you can send an eLetter using the eLetters link at the beginning of each article. Your response will be posted on Occupational and Environmental Medicine online within a few days of receipt (subject to editorial screening).

\section{www.occenvmed.com}

